\title{
LOS MIGRANTES NORUEGOS EN ALICANTE ¿HABLAN ESPAÑOL?
}

\section{Ann Elisabeth Laksfoss Cardozo \\ Universitetet i Stavanger, Norge}

\section{Sammendrag}

De siste 50 årene har tusenvis av nordmenn kjøpt bolig i Spania. De fleste sesongmigrerer mens noen få migrerer. Her analyseres noen sosiolingvistiske aspekter av kulturelle møter mellom nordmenn og spanjoler på 1970-tallet. Jeg fokuserer på hvordan språk ble til kulturell kapital der, hvilke språk nordmenn snakket der, og hvilke utfordringer norske organisasjoner og institusjoner møtte i Alicante. Teksten bygger på deler av min avhandling om transnasjonale norske migranter i Alicante (1965-2015).

Palabras clave: Migrantes noruegos; Alicante; Competencia; Lengua española; encuentros culturales

La movilidad de personas de un país a otro ha sido un fenómeno continuo durante los últimos 50 años. Esta movilidad se debe a la migración del sur al norte y del norte al sur. En Europa, ha habido mucha movilidad del este al oeste, del sur al norte y también, aunque en menores proporciones, del norte al sur. España es uno de los países europeos que más ha recibido migrantes, desde mediados de los años 80 y hasta la crisis financiera de 2006. Mucha de esa movilidad está relacionada con la historia colonial de América Latina y también con la de países del Magreb como Argelia y Marruecos. Sin embargo, otra parte de esta migración está relacionada con el rol de España como destino turístico para muchos europeos a partir de los años sesenta.

A partir de estas fechas empezaron a instalarse en España miles de personas del norte de Europa, británicos, alemanes, holandeses, pero también nórdicos. La 
gran mayoría de estas personas eran mayores con alguna enfermedad crónica que se veía aliviada al pasar temporadas largas en un clima más cálido. Otras personas se mudaron a España para ofrecer servicios a retirados de la misma nacionalidad, ya que la barrera lingüística de estos - era considerable. En su mayoría estos últimos migrantes eran jóvenes o familias con niños.

Este artículo analiza el contexto local y algunos aspectos sociolingüísticos de la migración de noruegos a Alicante desde 1965 a 2014. La mayoría de los noruegos que migran a España, van a enclaves turísticos en la Costa Blanca, la Costa del Sol, y las Islas Canarias. El tema de esta investigación se limita a la migración a Alicante.

El artículo forma parte de la investigación de una tesis doctoral en historia contemporánea (Cardozo, 2018). En la tesis se analizan las relaciones transnacionales entre noruegos en Alicante $e$ instituciones y organizaciones noruego-españolas en Alicante con instituciones y organizaciones en Noruega. Los datos recogidos de este proyecto me permitieron obtener mejores conocimientos del tema y expandir geográficamente el estudio de la tesis doctoral.

En Europa hoy en día existe un debate anti-inmigración que considera a las personas extranjeras como una amenaza para la cultura de muchos países. Con relación a este debate se critica a menudo a los inmigrantes porque supuestamente no se esfuerzan lo suficiente en aprender la lengua del país receptor. Por lo tanto, es interesante explorar la otra cara de la moneda: si los europeos del norte aprenden español al mudarse a España o no. No puedo con este estudio cualitativo concluir contundentemente si esto es verdad o no, ya que esta pregunta es muy amplia para mi estudio limitado a noruegos y suecos. Sin embargo, puedo elaborar algunos datos sobre el tema a partir de mis fuentes, basadas en 80 entrevistas y otros documentos recogidos sobre los nórdicos en Alicante, consultados en España como en Noruega (Laksfoss Cardozo 43-52, 324-326).

¿Hablan español los noruegos en Alicante? Según los artículos escritos por sociólogos, antropólogos e historiadores noruegos y españoles, que cubren el periodo entre 1965 y 2014 coinciden en que la gran mayoría de los noruegos retirados que residen parte del año en Alicante no hablan mucho español (Gustafson and Cardozo; Haug et al; Jurdao and Sánchez; Steen Jacobsen et al; Valero 
Temanummer: Spansk i Norge og det norske i den spansktalende verden.

Escandell). La gran mayoría sufría de alguna enfermedad. Solían pasar parte del año en Alicante y otra parte del año en Noruega. Precisamente esta migración circular hizo que fuera más difícil para ellos aprender el español. Otra razón pudo haber sido la cómoda situación económica de los noruegos, o sea la falta de necesidad económica. Los retirados noruegos traían sus pensiones y no estaban obligados a aprender el español para financiar su estadía. Fueron a destinos específicos alicantinos precisamente porque ya había escandinavos, ingleses, alemanes y holandeses instalados allí (Aubert; Casado-Diaz; Aledo and Mazón). A partir de la década de los años setenta, hubo además cierta infraestructura en términos de clubs, escuelas y congregaciones religiosas. Además, hubo otros individuos de habla noruega que vendían y que ofrecían servicios de salud. Más tarde, a partir de la década de los años ochenta, hubo incluso acceso a la televisión noruega (ilegalmente por satélite), y a periódicos noruegos; así mismo se establecieron vuelos directos entre muchas ciudades noruegas y Alicante. De esta manera fue relativamente fácil vivir en zonas costeras alicantinas sin saber español en la vida cotidiana. Los problemas comunicativos surgían cuando los noruegos tenían problemas de salud o contacto con algún representante del orden público.

Aunque la mayoría no hablaba español más allá de "buenos días" y "gracias", algunos noruegos sí que lo hacían. De hecho, varios informantes que llegaron al noroeste de Alicante en los años sesenta, me contaron que habían estudiado español en institutos de educación media en Noruega, o en casa con tutores privados, o en una universidad noruega o española. A veces esto era un proyecto familiar, como me explicó una de las informantes, que tomó clases con su padre en Oslo, ya que sus padres compraron en 1968 una vivienda cerca de Málaga. La tutora fue la hija de una española que residía en Oslo. Luego como consecuencia de ese primer aprendizaje del español, y varias vacaciones en España, la informante consiguió un puesto como enfermera en la Hacienda del Sol (Solgården) en Villajoyosa. Esta institución abrió en 1971 para ofrecer vacaciones a niños discapacitados noruegos. En Oslo, la informante había trabajado como enfermera en turno de noche en un hospital. Delso explicó que coincidieron varios factores para que ella se mudara a España: Su salud, la vida familiar y su agotador trabajo 


\section{Nordic Journal of Modern Language Methodology}

Temanummer: Spansk i Norge og det norske i den spansktalende verden.

nocturno. En otras palabras, deseaba un clima más cálido y cambiar de vida (Signe Delso).

Otros migrantes se dieron cuenta, una vez en Alicante, que realmente necesitaban mejorar sus conocimientos de español. A base de este mercado emergente, empezaron algunos noruegos y también españoles a ofrecer clases particulares. A largo plazo se establecieron inclusive academias de lengua noruega y española. Por lo tanto, el capital cultural del dominio de ambas lenguas, se convirtió en un capital económico a largo plazo.

Otro aspecto económico relacionado con la falta de dominio del idioma era que los migrantes que no entendían español tenían que pagar más por todo tipo de servicio, desde la vivienda hasta los bancos, los seguros etc., ya que dependían de consultores, intérpretes y otras personas que cobraban comisiones y tarifas extras. Los que no disponían de su propia casa o un gran capital se vieron obligados a aprender español rápidamente.

\section{El colegio noruego y otros colegios internacionales en Alicante}

Una de las razones por las cuales se empezaron a abrir colegios internacionales fue por los problemas de comprensión entre padres y profesores; y de los profesores con sus alumnos. Hubo un colegio francés en Alicante e inglés en Benidorm antes de que se fundara una escuela nórdica.

La iniciativa de algunas familias noruegas hizo que se fundara un colegio noruego en Alfaz del Pi. Una de las madres fundadoras viajó a Valencia justamente para mejorar sus conocimientos de español y dedicarse a su enseñanza del ELE en ese colegio. Una familia, que primero había ingresado a sus hijos en un colegio municipal, sufrió un choque cultural que sirvió como motivación para fundar un colegio noruego privado. Según contó la madre en una publicación con motivo de la celebración del aniversario de los 20 años del colegio noruego (Lund), varios padres opinaron que la escuela pública española de los años setenta (durante la dictadura de Franco) era demasiado estricta, teórica y autoritaria. Algunas familias se mudaron a Alicante con hijos de diferentes edades que no sabían nada o muy poco español y 
Temanummer: Spansk i Norge og det norske i den spansktalende verden.

a los que les fue difícil ingresar en un nuevo sistema escolar a la edad de 8, 10 o 14 años. De hecho, varios jóvenes se volvieron a Noruega por el choque cultural asociado al sistema educativo.

Al fundar el colegio noruego en 1972, el consejo de padres y fundadores acordó ofrecer clases de español a los alumnos desde el primer grado, reconociendo la importancia de aprender bien esta lengua. Sin embargo, al principio no se contrató un profesor de español nativo, ni un noruego con competencia formal en Filología Hispánica, sino que una de las madres noruegas impartió las clases. Puede ser que esto se debió a motivos de orden económico más que a prioridades pedagógicas. La persona en concreto, tomaba clases de castellano para poder enseñar lo que ella misma recién había aprendido. Sin embargo, este arreglo no duró mucho tiempo y el colegio noruego contrató a una profesora nativa de español.

Una profesora de español me contó que, aunque en el colegio noruego habían impartido clases de español desde el primer grado desde que ella trabaja allí (1986), todavía en 2013 había muy pocos alumnos que podían mantener una conversación en español. La mayoría de los alumnos llevaban poco tiempo en España. Los que eran capaces de hacerlo tenían familiares hispanohablantes o estaban practicando algún deporte en un club local (por ejemplo, equitación, balonmano o fútbol) y por lo tanto practicaban la lengua con jóvenes de su edad y con los entrenadores (María Pilar de la Cuesta Morán).

Desde los años finales de los sesenta hubo niños noruegos que recibieron su enseñanza en colegios españoles y por lo tanto aprendieron correctamente el español. Sin embargo, la zona alrededor de Benidorm era multicultural y pronto se fundaron varios colegios internacionales cuyas lenguas de enseñanza no eran el español. La existencia de las escuelas privadas e internacionales (la mayoría escuelas en las cuales las materias fueron impartidas en inglés) dependía de la geografía, pero también del poder adquisitivo de las familias. Hubo familias noruegoespañolas que mandaron a sus hijos a escuelas internacionales o colegios privados españoles en Benidorm. Incluso, hubo una familia que mandó a sus hijas al colegio francés en Alicante (Jens Kristian Grüner-Hegge; Anne Hawkins). Antes de que se abriera el colegio noruego, hubo durante varios años una escuela privada sueca en 


\section{Nordic Journal of Modern Language Methodology}

Temanummer: Spansk i Norge og det norske i den spansktalende verden.

Altea. A principios de los años setenta, se fundaron en Alfaz del Pi tanto el colegio noruego como el colegio británico. Esto demuestra que la zona era bastante variada en cuanto a la composición de la población y que no solamente se mudaron europeos del norte mayores, sino que también se instalaron familias con niños. Los que pudieron pagar las matriculas, mandaron a sus hijos a colegios privados, sin importar la nacionalidad de la familia. Probablemente, los niños que se educaron en institutos con programas en inglés, francés o noruego, no aprendieron tanto español (y nada del valenciano) como los niños que hicieron toda su escolarización dentro del sistema educativo español. Sin embargo, hubo excepciones. He podido comprobar que algunos hijos de noruegos que hicieron toda su educación en colegios internacionales, aprendieron bien varias lenguas, y completaron grados universitarios en España. El hecho de nacer en la zona, de tener amigos y vecinos españoles hizo que se integraran en la sociedad española.

\section{Cambios y el valenciano}

Después de la muerte del dictador Franco en 1975, y el fin de su política centralista e intolerante en cuanto a plurilingüismo, hubo un proceso de democratización en todo el país. Hasta el 1983 hubo solamente una lengua de instrucción en Alicante. Después de esa fecha en los municipios alrededor de Benidorm, las escuelas públicas empezaron a impartir las clases en valenciano según la nueva legislación de las comunidades autónomas (Comunidad Valenciana; Cardozo 121-4). Esto suponía un reto extra para los inmigrantes jóvenes, ya que tuvieron que aprender dos lenguas. A menudo los padres no estaban capacitados para ayudar a sus hijos con las tareas en valenciano y la actitud de los inmigrantes noruegos en cuanto a esta lengua fue más bien crítica. Algunos mantuvieron que el valenciano era simplemente una manera de discriminarles a ellos como inmigrantes. Algunos padres que sí hablaban muy bien español lamentaban la exigencia del valenciano, ya que hubieran preferido que sus hijos aprendieran mejor el inglés. Veían al valenciano como una lengua poco útil. Sin embargo, aunque solamente hay unos cinco millones de noruego-parlantes en el mundo, los noruegos que mandaron sus 


\section{Nordic Journal of Modern Language Methodology}

Temanummer: Spansk i Norge og det norske i den spansktalende verden.

hijos a aprender la lengua noruega en el colegio noruego, estimaban que la lengua noruega fuera valiosa y útil. Varios padres confirmaron que precisamente mandaron a sus hijos al colegio noruego para que sus hijos tuvieran un noruego fluido. Posiblemente la fluidez en el noruego tenía más que ver con la cultura, ciudadanía, pasaporte e identidad.

Para algunos inmigrantes, las políticas protectoras hacia el valenciano constituían barreras e inconveniencias. Para poder entrar en algunas carreras universitarias muy populares, como medicina, no se podía obtener notas mediocres en ninguna materia. Hubo inmigrantes que vieron fracasar su sueño de ser médico por una mala nota en valenciano.

\section{La integración y el trabajo}

Algunos de los noruegos que se instalaron en Alicante encontraron novios y formaron familias en Alicante. A través de esta integración aprendieron tanto la cultura como la lengua española. No solamente la adquisición de conocimientos lingüístico sino también los códigos culturales. Una de las informantes explicó que entender la lengua en su contexto cultural fue mucho más complejo de lo que ella se imaginaba. Al principio se confundía porque pensaba que había entendido el mensaje. Sin embargo, estaba dudando de la semántica. Si la invitaban "a comer" ella hacía preguntas como “¿a qué hora?” Esto se percibía como redundante ya que "comer" en Alicante tiene un significado mucho más concreto. Si el verbo "comer" en noruego solamente identifica el acto de meter comida en la boca - no importa a qué hora, en Alicante se usa como sinónimo de almorzar y con un horario específico (Siri Lund).

Lund también explicó sobre un aspecto de adaptación cultural local de algunos de los empleados en un supermercado frecuentado por noruegos. Estos empleados se acomodaron a la nueva clientela nórdica de una forma específica. Los empleados esperaban de la clientela que respetara y conociera los códigos culturales locales. Por ejemplo, les molestaba que los nórdicos ni saludaran al entrar ni utilizaran las palabras de cortesía comunes en español al salir. Algunos de los nórdicos eran muy 
Temanummer: Spansk i Norge og det norske i den spansktalende verden.

directos y eran percibidos como rudos e irrespetuosos por los empleados. Unos no hablaban español, pero para recompensar hablaban más alto en noruego. La respuesta de los empleados al entrar un cliente nórdico fue cantar en lugar de mostrar su irritación. Los nórdicos por su parte interpretaron el canto como expresión de buen humor, extroversión y buen servicio. Esto coincidía con los estereotipos que los noruegos tenían sobre los españoles y con sus expectativas de cómo debían ser tratados como buenos clientes. De esta manera el canto no producía confrontación entre los empleados y los nórdicos, pero tampoco un contacto verdadero de interacción y comprensión.

Otro informante también me comentó acerca de la costumbre de algunos empleados españoles de cantar al trabajar, me contó que a su padre noruego le había parecido sorprendente y admirable oír que los empleados cantaran mientras trabajaban en unos astilleros en El Campello (Grüner-Hegge). Es posible que el hecho de que cantaran fuera una manera de oponerse a los cambios de jefes y de clientes. Igualmente puede ser que cantaran como manera de solidarizarse con sus compañeros de trabajo.

Mientras que la sociedad española era muy jerárquica, no era siempre evidente dónde tendrían que estar los noruegos en esta jerarquía. Para los españoles locales, los nórdicos que no sabían comunicarse en español eran torpes y poco civilizados. Esto coincide con el mito y el esencialismo de lo que eran los españoles para los noruegos. Los españoles supuestamente estaban siempre sonrientes, alegres, sencillos, agradables y siempre contaban chistes. Si cantaban debía ser porque estaban de buen humor. Una cita del archivo de la Hacienda del Sol de Villajoyosa demuestra esta actitud por parte de una administradora noruega:

Som Antonio selv sier - han ikke bare har sitt arbeid der, men hele sitt hjerte, og dette gjenspeiler seg $i$ hele hans stab som varmer enhver kald nordisk viking til hjerteroten. En blir glad når en er sammen med disse deilige menneskene - det må være solvarmen! Como dice Antonio - no solamente tiene su labor aquí, sino que se ha metido con todo corazón y esto se refleja en su plantilla que derrite a cualquier vikingo congelado. Uno se pone alegre cuando uno está junto a estas personas encantadoras - jdebe ser el calor del sol! (Cardozo 240) 
Temanummer: Spansk i Norge og det norske i den spansktalende verden.

El mismo cocinero de la Hacienda del Sol Antonio Soler Galiana fue descrito como «omnipresente» y servicial por un cura noruego. Esta omnipresencia y actitud de estar dispuestos a rendir servicio, conlleva connotaciones de sumisión. Los empleados españoles siempre estaban dispuestos a agradar a sus patronos y los patronos disfrutaban. En fin, este es solamente un ejemplo de que los españoles empleados por la institución fueron admirados por los noruegos por capacidades como «buen humor» y «trato humano». Un cura también reconoció la capacidad de trabajar mucho (omnipresente). Pero en las fuentes del archivo de la Hacienda del Sol no aparecen cumplidos por ejemplo refiriéndose al intelecto, al profesionalismo o creatividad de los empleados españoles.

Los empleados españoles y noruegos en el área de Alicante no fueron tratados de manera igualitaria en los años setenta. Sus salarios seguían diferentes escalas y además tomaban pausas a diferentes horas. La mayoría de los españoles tenían puestos de mantenimiento o limpieza, mientras que los noruegos eran administradores o profesionales de salud (Riksarkivet). Por lo tanto, hubo división étnica por costumbres, lenguas y puestos de trabajo.

Paulatinamente se nivelaron las diferencias de salario, no subiendo los salarios españoles sino más bien bajando los salarios de los noruegos. Esto también hizo que se incrementara el respeto a los españoles. También ayudó que algunos españoles tuvieran cargos directivos.

La estrategia y el énfasis en relaciones personales de los españoles, que incluía retener de memoria los nombres de los clientes, hizo que los nórdicos sintieran que habían formado nuevas amistades con españoles, especialmente los que proveían servicios. Los camareros de los bares, la empleada del banco y el señor del kiosco por su lado eran profesionales y amables, pero lo más probable es que tejían una red leal de clientes como estrategia para su negocio. Los noruegos que abrieron sus propios negocios adaptaron esta táctica con el trato más personalizado, poniendo énfasis en cuanto a los nombres, saludando y despidiéndose formalmente de sus clientes.

Las entrevistas y otros documentos consultados han sugerido que para los españoles los nórdicos eran cerrados, serios, inflexibles - demasiado directos y 


\section{Nordic Journal of Modern Language Methodology}

Temanummer: Spansk i Norge og det norske i den spansktalende verden.

desconfiados. Al escuchar cómo la mayoría nórdica hablaba español incorrectamente, cometiendo errores en la conjugación de los verbos, omitiendo el subjuntivo, y sin prestar atención a la concordancia de los artículos y adjetivos, los españoles concluyeron que los nórdicos debían ser infantiles y simplistas. A los noruegos que hablaron español bien, los españoles les dieron apodos en español como Jon Svanberg - más conocido como Juan Montecisne o simplemente Juanito en Alfaz del Pi.

Los noruegos hispanohablantes acumularon un capital cultural que usaron para poder vender servicios y productos a noruegos recién llegados y para aumentar su propia posición local en la sociedad española. En los municipios costeros de Alicante, los turistas y los migrantes del norte de Europa han tenido un poder adquisitivo considerable y por lo tanto son deseados como clientes en la economía local. Gran parte de la economía de Alicante depende de la presencia de estos grupos. Por lo tanto, cualquier confrontación o crítica abierta se evitaba y se toleraba un comportamiento que con otros migrantes no solía permitirse.

Es verdad que dentro del grupo de noruegos hubo diferencias socioculturales. Hubo retirados con fortunas acumuladas y pensiones altas, y también hubo familias jóvenes que tuvieron que empezar desde cero y construir su vida a partir de empleos temporales, venta por comisión, horas pagadas sin derecho a pensiones, etc. Otros tenían apenas sus pensiones mínimas o se mudaron con pensión permanente de invalidez. Sin embargo, incluso los que tenían menos recursos económicos, fueron a menudo tratados por los españoles, más según su pertenencia al grupo de noruegos que según su capital económico. De esta forma la gran mayoría de los noruegos que han vivido en Alicante pertenece a la clase media/media alta. En cuanto a la relación entre competencias de lengua y clase social, es bastante evidente que los que no tenían mucho capital económico tuvieron que aprender español para conseguir entrar en el mercado laboral local. Los que no aprendieron español en su mayoría retornaron a Noruega porque no pudieron financiar su estadía. 
Nordic Journal of Modern Language Methodology

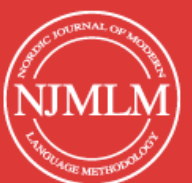

2019, 7 (2), 74-88 Peer reviewed Temanummer: Spansk i Norge og det norske i den spansktalende verden.

\section{¿Quiénes aprendieron el español y cómo?}

Como mencioné anteriormente, los noruegos que necesitaban comunicar en español para conseguir un empleo, por sus propios negocios, y los que se casaron con españoles, aprendieron español. Algunos estudiaron español en Noruega antes de mudarse. Otros tomaron cursos en España y algunos aprendieron la lengua por su propia cuenta. Algunos de los llamados profesores no tenían formación como profesores de lengua, sino que eran individuos buscando trabajo. En épocas de crisis, la venta de casas no daba suficientes ingresos y por lo tanto algunos vendedores decidían convertirse en "profesores" de español. Raras veces se les pedía certificados o exámenes oficiales a estos instructores y los métodos y los resultados variaban. No obstante, se creaba empleo y se produjeron encuentros culturales entre españoles y migrantes en Alicante. Pocos nórdicos se inscribieron a las escuelas oficiales de idioma, pero esto también tiene que ver con la intensidad de estos cursos y su existencia en los municipios donde no vivían la mayoría de los nórdicos. Si bien Valencia tuvo un centro desde 1960, en Alicante solamente se abrió una Escuela Oficial de Idiomas en el 1968. Los centros de Benidorm y Torrevieja no abrieron hasta más tarde, en los años ochenta.

$Y$ los que no aprendieron, ¿Qué hicieron? Algunos de los que no aprendieron español expresaron decepción, la mayoría de mis informantes tenía la intención, un proyecto que les inspiraba a aprender el español, una lengua que les parecía bonita, útil y hasta romántica. Antes de mudarse a Alicante pensaban en este proyecto como un reto positivo y posible. Durante las entrevistas algunos de los informantes expresaron vergüenza, porque sentían que no habían logrado su propósito. El hecho de tener que contestar preguntas sobre sus conocimientos de la lengua española a una investigadora les causaba molestia. Algunos lamentaban ser dependientes de otros. Otros mencionaron que sus vidas en España no tenían nada que ver con las de otros migrantes en los países nórdicos, simplemente no se podían comparar esencialmente por motivos económicos. Mientras que los inmigrantes hacia el norte necesitaban un empleo y tenían que aprender una lengua local, los nórdicos en 
Nordic Journal of Modern Language Methodology

2019, 7 (2), 74-88 Peer reviewed

Temanummer: Spansk i Norge og det norske i den spansktalende verden.

Alicante venían financiados por unas pensiones que en el contexto español eran generosas (Cardozo 136-7).

Los que no hablaron español y no vivían en Alicante sino parte del año, a menudo necesitaban organizar alguien que les cuidara la casa, mantuviera el jardín y entrara el correo. Estos servicios se organizaron en muchas lenguas en los municipios costeros de Alicante. Los nórdicos tuvieron que buscar soluciones más costosas (sin embargo, menos costosas que alternativas similares en el norte de Europa) en cuanto a todo tipo de servicios, porque en lugar de buscar ofertas locales entraron en un mercado creado para turistas y pensionistas del Norte de Europa quienes necesitaban los mismos servicios que los demás, más un extra en términos de lenguaje y comunicación. Un ejemplo claro es que los europeos del norte a menudo compraban o alquilaban casas de escandinavos. $Y$ de la misma forma en cuanto a banco, seguro, teléfono, mantenimiento y limpieza. Se sentían más cómodos comunicando en su lengua materna. Esperaban que la solidaridad étnica les protegiera. A veces acertaban y otras veces los vendedores noruegos les defraudaban o les engañaban (Cardozo 2018).

Los que no sabían español tuvieron que llevar intérprete a las citas con oficinas públicas o buscar un médico de habla escandinava. Sus preferencias en términos de restaurantes y bares a menudo se limitaban a los que disponían de empleados que hablaban inglés u otra lengua escandinava. No se trata simplemente de lengua, sino a menudo de conocimientos culturales y preferencias en términos de ciertos productos. Hoy en día, muchos de estos establecimientos pueden cargar precios más altos porque son identificados como parte de la oferta de turismo. A menudo no ofrecen menú del día (una combinación de tres platos incluida la bebida) como es usual en restaurantes españoles a la hora de comer. En cambio, abren con horario continuado, algo muy conveniente para los que prefieren seguir el ritmo de las comidas al horario escandinavo (cenar a las cinco de la tarde). Muchas veces los servicios se encarecen porque, aunque hay compañías que anuncian que ofrecen servicios en muchas lenguas, realmente no disponen de esa competencia y tienen que buscar algún externo al cuál hay que pagar. 


\section{Nordic Journal of Modern Language Methodology}

Temanummer: Spansk i Norge og det norske i den spansktalende verden.

Las ventajas de saber ambas lenguas, una lengua escandinava y el español, son sociales obviamente ya que los plurilingües pueden escoger amigos y actividades en diferentes ambientes. A parte de las ventajas sociales también hay ventajas económicas en término de empleo o de acceso a clientes. Una señora que se mudó a Alfaz del Pi en 1968 contó que su permiso de trabajo dependía de sus recursos lingüísticos ya que la empresa multinacional que la contrataba requería de alguien que supiera tanto el noruego como el inglés y el español.

Algunas de las parejas de retirados dividían la tarea de la lengua, o sea que uno de los dos entendía más que el otro. Varios hablaron del uso pragmático de lenguaje no-verbal, de teléfonos inteligentes y de programas de traducción como el Google Translate. Los que no sabían comunicarse en español pocas veces declararon esto como un problema o reto. Al contrario, decían que a pesar de la barrera lingüística estaban satisfechos. Para la mayoría el hecho de no saber español no es un problema en esta zona costera de España donde la población nacida en el extranjero a menudo excede el porcentaje de la población nacida en España (es el caso de más de 20 municipios en Alicante).

\section{Ventajas y conclusiones}

¿Cuáles fueron las ventajas o desventajas de los migrantes como resultado de sus conocimientos o capacidades de comprender y participar en las interacciones orales o escritas en castellano (y en valenciano)? Los estudios sobre inmigrantes a Noruega a menudo subrayan que la falta de conocimiento del noruego es un gran obstáculo a nivel individual y dificulta la integración en la sociedad noruega. Al mismo tiempo los noruegos que migran a otros países a menudo no sienten la misma obligación de integrarse o de aprender una nueva lengua. En estos casos, los noruegos asumen que es suficiente utilizar una lingua franca como el inglés. Muchos conocen el área que visitan en España porque ya han pasado vacaciones allí. La expansión de la estadía del turismo a la migración no se ve como algo fundamentalmente diferente de las vacaciones anteriores. Muchos indican lo obvio, o 


\section{Nordic Journal of Modern Language Methodology}

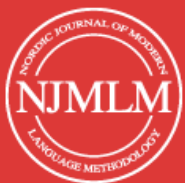

2019, 7 (2), 74-88 Peer reviewed

Temanummer: Spansk i Norge og det norske i den spansktalende verden.

sea, que es complicado aprender una nueva lengua y que no la necesitan en su rutina diaria.

La barrera lingüística supone un reto individual para cada inmigrante y además supone un reto estructural a nivel de la sociedad anfitriona. Los profesionales talentosos no aprovechan sus talentos y pueden ser segregados o discriminados.

A lo largo del texto he discutido algunos aspectos sociolingüísticos de los migrantes noruegos en Alicante. Algunos han aprendido el español, la mayoría no lo ha hecho, pero no ha sido por falta de interés. Primordialmente no necesitan hablar el español ni por razones económicas ni por razones sociales. Los españoles que he entrevistado tampoco exigen ni esperan que los nuevos vecinos aprendan el español. Muchos los consideran más como turistas que como residentes. Mi principal intención ha sido reflexionar sobre la diversidad lingüística en la provincia de Alicante entre migrantes noruegos jóvenes y mayores, los recién llegados y los que llevan allí varias décadas. Alicante ha cambiado como consecuencia de los cambios políticos tanto del gobierno central como del local, y porque el turismo y la vivienda secundaria han supuesto modificaciones, a veces dramáticas, en ámbitos como la cultura, la economía y la política. Para los migrantes ha sido más costoso no hablar español. Mientras que los que sí que lo aprendieron, se beneficiaron en aspectos tanto económicos como sociales y culturales.

\section{Bibliografía}

Aubert, Wilhelm. Det skjulte samfunn Oslo: Pax, 1969. Impreso.

Cardozo, Ann Elisabeth Laksfoss. "Mer enn sol og varme. Transnasjonale norske migranter i Alicante 1965-2014." PhD, Stavanger: Universitetet i Stavanger, 2018. Web 15 de mayo de 2018. http://hdl.handle.net/11250/2490680

Casado-Díaz, María Ángeles. "Retiring to Spain: An Analysis of Differences among North European Nationals." Journal of Ethnic and Migration Studies 32.8 (2006): 1321-1339. Impreso.

Comunidad Valenciana. Ley 4/1983 de 23 de noviembre de 1983 "Llei d'Ús i Ensenyament del Valencià." Web 12 de febrero de 2014. http://www.dogv.gva.es/portal/ficha_disposicion.jsp?L=1\&sig=0428\%2 F1983 


\section{Nordic Journal of Modern Language Methodology}

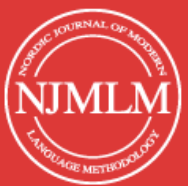

2019, 7 (2), 74-88 Peer reviewed Temanummer: Spansk i Norge og det norske i den spansktalende verden.

Gustafson, Per and Ann Elisabeth L Cardozo."Language Use and Social Inclusion in International Retirement Migration" Social Inclusion 5.4 (2017): 69-77. Impreso.

Haug, Bente et al. "Little Norway in Spain: From Tourism to Migration." Annals of Tourism Research 34.1 (2007): 202-22. Impreso.

Helset, Anne et al. "Jubilados noruegos en España: Perspectivas de una cuarta edad para personas de la tercera edad." La migración de europeos retirados en España. Ed. Vicente Rodríguez Rodríguez et al. Madrid: Consejo Superior de Investigaciones Científicas, 2005. Impreso.

Jacobsen, Jens Kristian Steen et al. "Introverts abroad? Long-term visitors' adaptations to the multicultural tourism context of Costa Blanca, Spain." Journal of Tourism and Cultural Change 7.3 (2009): 190-202. Impreso.

Jurdao, Francisco and María Sánchez. España, asilo de Europa. Barcelona: Planeta, 1990. Impreso.

Lund, Siri et al. (1992) "Den norske skole Costa Blanca 1972-1992. Skolens historie gjennom 20 år," Alfaz del Pi: DnsCB. Impreso.

Mazón, Tomás and Antonio Aledo ed. Turismo residencial y cambio social. Nuevas perspectivas teóricas y empíricas. Alicante: Cam, Fundación Frax, UA, 2005. Impreso.

Mobility and Inclusion in a Multilingual Europe (MIME) 2014-2018. Grant agreement nr. 613334. Web 15 de mayo de 2018. http://www.mime-project.org/

Riksarkivet "Solgården" (1968-1990)

Valero Escandell, José Ramón. "La inmigración en la provincia de Alicante 19601986." PhD, Alicante: Universidad de Alicante, 1989. Web 22 de febrero de 2013. http://rua.ua.es/dspace/handle/10045/7581

\section{Lista de entrevistas}

Delso, Signe, 29.05.2013, Alfaz del Pi

Grüner-Hegge, Jens Kristian, 05.03.2013, La Nucia

Hawkins, Anne, 28.05.2013, Alfaz del Pi

Kindem, Tim, 11.06.2013, Torrevieja

Kindem, Turid, 10.06.2013, Torrevieja

Lund, Siri, 25.06.2013, Alfaz del Pi

Morán, María Pilar de la Cuesta, 17.06.2013, Alfaz del Pi 